\title{
Anti-C-met Monoclonal Antibody SAIT301
}

National Cancer Institute

\section{Source}

National Cancer Institute. Anti-C-met Monoclonal Antibody SAIT301. NCI Thesaurus.

Code C119619.

A humanized monoclonal antibody targeting the alpha chain of the extracellular domain of human hepatocyte growth factor receptor (HGFR or c-Met), with potential antineoplastic activity. Anti-c-Met monoclonal antibody SAIT 301 binds to c-Met, thereby preventing both binding of its ligand, HGF, and the subsequent activation of the HGF/cMet signaling pathway. In addition, SAIT 301 induces c-MET internalization and subsequent degradation, which further inhibits c-Met-mediated signaling. This leads to a reduction in the proliferation of c-Met-expressing cancer cells. c-Met, a proto-oncogene receptor tyrosine kinase overexpressed in certain cancer cell types, is involved in various tumors. 